\title{
Non-Dipole and Regional Effects on the Geomagnetic Dipole Moment Estimation
}

S. A. Campuzano ${ }^{1,2}$, F. J. Pavón-Carrasco ${ }^{3}$, M. L. Osete ${ }^{1,2}$

${ }^{1}$ Dpto. de Física de la Tierra, Astronomía y Astrofísica I, Universidad Complutense de Madrid (UCM), Avd. Complutense s/n, 28040-Madrid, Spain. E-mail: sacampuzano@ucm.es; mlosete@ucm.es.

${ }^{2}$ Instituto de Geociencias (IGEO) CSIC, UCM, Ciudad Universitaria, 28040-Madrid, Spain.

${ }^{3}$ Istituto Nazionale di Geofisica e Vulcanologia (INGV), Via Vigna Murata, 605, 00143-Roma, Italy. E-mail: javier.pavon@ingv.it.

Abbreviated title: Differences in geomagnetic dipole moment estimation 


\begin{abstract}
. (20-30 sentences)
\end{abstract}
The study of the temporal evolution of the dipole moment variations is a forefront research topic in Earth's Sciences. It constrains geodynamo simulations and is used to correct the cosmogenic isotopes production informing about the past solar activity and to study possible correlations between the geomagnetic field and the climate. In this work, we have analysed the main error sources in the geomagnetic dipole moment computation from palaeomagnetic data: the influence of the non-dipole terms in the average approach, the inhomogeneous distribution of the current palaeomagnetic database and the averaged procedure used to obtain the evolution of the dipole moment. To evaluate and quantify these effects, we have used synthetic data from a global model based on instrumental and satellite data, the International Geomagnetic Reference Field for eleventh generation (IGRF-11). Results indicate that the non-dipole terms contribute at global scale less than $6 \%$ in the averaged dipole moment, whereas the regional non-dipole contribution can suppose deviations up to $35 \%$ in some regions such as Oceania and different temporal trends with respect to the global dipole moment evolution in other ones, such as Europe and Asia. A regional weighting scheme seems the best option to mitigate these effects in the dipole moment average approach. But, when directional and intensity palaeomagnetic information is available at global scale, and in spite of the inhomogeneity of the database, global modelling presents more reliable values of the geomagnetic dipole moment.

Key words: geomagnetism, palaeomagnetism, archaeomagnetism, geomagnetic dipole moment, geomagnetic field modelling. 


\section{Introduction.}

The dipole field is the major contributor to the geomagnetic field at the Earth's surface. Its time evolution plays a significant role to constrain the geodynamo models (e.g., Glatzmaier and Roberts, 1995; Christensen et al., 2010). In addition, accurate determinations of the past dipole moment are needed for appropriately correcting the production rate of cosmogenic isotopes $\left({ }^{14} \mathrm{C},{ }^{10} \mathrm{Be}\right)$ used for reconstructing scenarios of the past solar activity (e.g., Muscheler et al., 2007; Vieira et al., 2011; Roth and Joos, 2013). Finally, geomagnetic dipole moment evolution at decadal and centennial time scales is necessary to address debated questions as the possible link between geomagnetic field variations and Earth's climate (e.g., Gallet et al., 2005; Usoskin et al., 2008, Genevey et al., 2013).

The dipole moment (DM) can be estimated when a global geomagnetic model is available. The spherical harmonic analysis (SHA) is the methodology usually used in the generation of global models of the Earth's magnetic field (Whaler and Gubbins, 1981). This technique is based on the SH expansion developed by Gauss in 1838, being the potential of the internal geomagnetic field established at any point $(r, \theta, \lambda)$ over the Earth's surface:

$$
\mathrm{V}(\mathrm{r}, \theta, \lambda, \mathrm{t})=\mathrm{R} \sum_{\mathrm{n}=1}^{\mathrm{N}} \sum_{\mathrm{m}=0}^{\mathrm{n}}\left(\frac{a}{\mathrm{r}}\right)^{\mathrm{n}+1} \mathrm{P}_{\mathrm{n}}^{\mathrm{m}}(\cos \theta)\left(\mathrm{g}_{\mathrm{n}}^{\mathrm{m}}(\mathrm{t}) \cdot \cos \mathrm{m} \lambda+\mathrm{h}_{\mathrm{n}}^{\mathrm{m}}(\mathrm{t}) \cdot \sin \mathrm{m} \lambda\right)
$$

where $a$ is the mean radius of the Earth $(a=6371.2 \mathrm{~km}), P_{n}^{m}$ are the associated Legendre functions with integer degree $n$ and integer order $m, \cos m \lambda$ and $\sin m \lambda$ the Fourier functions, and the $N$ is the maximum degree of the spatial expansion. $g_{n}^{m}(t)$ and $h_{n}^{m}(t)$ are the spherical harmonic coefficients, also denoted as Gauss coefficients. 
The Dipole Moment (DM) is easily calculated from the three first Gauss coefficients.

These coefficients $\left(\mathrm{g}_{1}{ }^{0}, \mathrm{~g}_{1}{ }^{1}\right.$ and $\left.\mathrm{h}_{1}{ }^{1}\right)$ provide the contribution of an inclined geocentric dipole, and the DM can be obtained as (see Jacobs, 1991):

$$
D M=\frac{4 \pi}{\mu_{0}} a^{3} \sqrt{\left(g_{1}^{0}\right)^{2}+\left(g_{1}^{1}\right)^{2}+\left(h_{1}^{1}\right)^{2}}
$$

where $\mu_{0}$ is the magnetic permeability of the free space $\left(\mu_{0}=4 \pi \cdot 10^{7} \mathrm{VsA}^{-1} \mathrm{~m}^{-1}\right)$.

When only the axial geocentric dipole is considered, i.e. aligned with the Earth's rotation axis, the dipole moment derives in the Axial Dipole Moment (ADM):

$$
A D M=\frac{4 \pi}{\mu_{0}} a^{3}\left|g_{1}^{0}\right|
$$

Nowadays, a dipole tilted by approximately $11^{\circ}$ accounts for more than $98 \%$ of the geomagnetic field observed on the Earth's surface. The IGRF (International Geomagnetic Reference Field) models describe the evolution of the field during the last century. Their last generation, the IGRF-11 (Finlay et al., 2010), covers the time span from 1900 to 2010 and is developed by using instrumental data and satellite data (for the last decades). During the last century, both DM and ADM are decreasing with rates around $50 \cdot 10^{-3} \mathrm{Am}^{2} / \mathrm{yr}$.

To extend the knowledge of the field variations to the past, historical directional data (Jonkers et al., 2003), which came from shipboard for navigational purposes, have been used in global modelling. The GUFM1 model (Jackson et al., 2000) is the model based on historical and instrumental data collected from 1590 to 1990 AD. But, due to the lack of historical intensity data before 1832 (Gauss, 1833), when Gauss developed a method for its measurement, this models had to assume an estimation of the temporal evolution of the first Gauss coefficient $\left(g_{1} g\right)$ prior to this epoch. Jackson et al. (2000) extrapolated linearly the value of this coefficient at 1840 
and they assumed a constant rate of temporal evolution of $15 \mathrm{nT} / \mathrm{yr}$, which corresponds with the average value of the time derivative of $g_{1}^{0}$ from 1850 to 1990.

Prior to $1590 \mathrm{AD}$, there are no direct measurements of the geomagnetic field elements (declination, $D$, inclination, $I$, and intensity, F), and the description of the field is based on indirect measurements of magnetized materials, such as sediments, lava flows, or heated archaeological artefacts. Each provides a different kind of palaeomagnetic information due to the different processes involved in its remanence acquisition.

The archaeomagnetic and lava flow data acquire their magnetization by a thermoremanence (TRM) mechanism. The archaeomagnetic data come from archaeological heated structures as pottery, tiles or bricks. They recorded the geomagnetic field acting during their last heating-cooling process. In the case of the lava flows, the magnetization was recorded during their natural cooling after the eruption. If the age of these cooling events is wellcontrolled, these data provide spot records of the ancient geomagnetic field. For this reason, detailed reconstructions of the geomagnetic field variations generally use this kind of data (e.g. Kovacheva et al., 2009; Genevey et al., 2013).

In contrast, sediments acquire a magnetization throughout depositional and/or postdepositional remanent magnetization processes (DRM and/or pDRM, respectively). This magnetization mechanism is delayed due to the compaction time required to lock in the magnetization. Consequently, geomagnetic field variations recorded by sediments are smoothed and global models derived from this kind of data present smaller variation of the geomagnetic field elements (Korte et al., 2009). In addition, from sedimentary data only relative intensities can be determined (e.g. Tauxe, 1993) in contrast to archaeomagnetic and volcanic data, which provide absolute palaeointensities. 
In terms of data distribution, the present the spatial and temporal distribution of the

archaeomagnetic and volcanic data is very inhomogeneous (Fig.1): for the last 14000 years the spatial distribution presents a clear lack of data in the Southern Hemisphere and a high concentration in the European region. In time, $83 \%$ of the data are concentrated in the last 3000 years, whereas the remaining $17 \%$ is distributed between 12000 and 1000 BC (Fig.1). The sedimentary data present a slightly better distribution in both space and time (Donadini et al., 2009), and then some authors (e.g. Korte et al. 2009, 2011; Licht et al., 2013) preferred to include them in the geomagnetic field reconstructions.

Following the above mentioned, the time evolution of the dipole moment given by the global models depends on the data used. On one hand, the archaeomagnetic and volcanic data provide higher temporal variability, but an overfitting of the available data could produce artificial high frequency in the temporal variability. On the other hand, the inclusion of sediment data increases the smoothness of the dipole moment variability. If we take into account the behaviour of the geomagnetic field during the last 170 years (available time span for the GUFM1 and IGRF models), the dipole moment presents a slow temporal evolution. This could be in agreement with the use of sediment data, but the problem arises from that the true frequency content of dipole moment changes is still not well-known for the last millennia. For this reason, we prefer to use only archaeomagnetic and volcanic data in our study, avoiding the different problems related to the use of sediment data.

An habitual practice to estimate the dipole moment from palaeomagnetic data is by using the geomagnetic field elements $F$ and $I$ and calculating the so-called Virtual Dipole Moment $\left(\mathrm{VDM}_{\mathrm{i}}\right)$ as follows (e.g. Genevey et al., 2008):

$$
V D M_{i}=\frac{4 \pi F_{i} a^{3} \sqrt{1+3 \cos ^{2} I_{i}}}{2 \mu_{0}}
$$


where the sub-index $i$ indicates the value of the VDM for an individual point on the Earth's surface. However, not all the intensity data available in the current palaeomagnetic database is corresponded by an inclination data. This is a common problem in archaeomagnetic studies, for example, when archaeointensities are determined from ceramic fragments where the orientation at the time of cooling is not known. In these cases, the $\mathrm{VDM}_{\mathrm{i}}$ cannot be estimated and it is commonly substituted by the Virtual Axial Dipole Moment $\left(\mathrm{VADM}_{\mathrm{i}}\right)$, obtained as:

$$
V A D M_{i}=\frac{4 \pi}{\mu_{0}} \frac{F_{i} a^{3}}{\sqrt{1+3 \sin ^{2} \phi_{i}}}
$$

where $\phi_{i}$ is the latitude of the studied site. In palaeomagnetism, the common procedure to analyse the evolution of the virtual (axial) dipole moment at millennial timescale is by averaging local values of $\mathrm{V}(\mathrm{A}) \mathrm{DM}_{\mathrm{i}}$ to obtain a mean $\mathrm{V}(\mathrm{A}) \mathrm{DM}$ at regional or global scales (e.g. Yang et al., 2000; Macouin et al., 2004; Genevey et al., 2008). The best averaging procedure is still an open question and different authors have followed distinct approaches (see Genevey et al., 2008 for a deeper discussion).

The main objective of this work is to assess the reliability of the different ways proposed in the literature for magnetic dipole moment determinations from palaeomagnetic data. First (Section 2), we carry out a quantitative determination of the non-dipole effect when an averaging process is considered. This effect is produced because the geomagnetic field at the Earth's surface, which is recorded by a palaeomagnetic material, contains information of the whole field, not only from the dipole field. The main assumption of palaeomagnetic studies is that the nondipole contribution of the geomagnetic field is cancelled by averaging.

Next section (Section 3) is focused on the impact of the sparse palaeomagnetic data distribution (see Fig. 1) on the computation of the global averages of the virtual dipole moment. The strong geographical bias of the intensity database toward Eurasia might likely produce 
erroneous estimations of the global V(A)DM. Korte and Constable (2005b) noticed that some care had to be taken to properly weight the data as a function of their location. Genevey et al. (2008) proposed a simple first-order weighting scheme. We study the reliability of this kind of averaging procedures. We denote this analysis as regional effect.

In the last section (Section 4) we study the limitations of the current palaeomagnetic database to generate geomagnetic field models. During the last decades, global geomagnetic models based on palaeomagnetic data have been developed (Korte and Constable, 2003, 2005a, 2011; Korte et al., 2009, 2011; Licht et al., 2013; Pavón-Carrasco et al., 2014). These models allow a direct estimation of the (A)DM (Eqs. 2 and 3). However, they are based on databases strongly biased (see Fig. 1). The objective of this section is to evaluate the effect of the use of a sparse database as input data in the models and to determinate how the Gauss coefficients are affected indirectly for the database used. Henceforth this effect will be called as regional indirect effect.

\section{Non-dipole effect}

Global averages of the $\mathrm{V}(\mathrm{A}) \mathrm{DM}_{\mathrm{i}}$ are commonly developed in palaeomagnetism in order to determinate the long-scale temporal evolution of the geomagnetic dipole moment. The main assumption is that the non-dipole contribution of the field is cancelled when these averages are calculated. To check the reliability of this assertion, we propose to work with the IGRF-11 model, which spans between the 1900 and 2010.

The IGRF-11 model was generated using instrumental data collected from geomagnetic observatories and satellites (CHAMP, Ørsted and SAC-C missions). This model is based on a spherical harmonic expansion whose maximum degree, $N$, is chosen so that the coefficients of the model are reliably determined given the available coverage and quality of observations. For 
IGRF-11, $N$ was chosen to be 10 up to 1995 ; thereafter it is extended to $N=13$ to take advantage

$$
\begin{gathered}
\sigma_{V A D M}=\frac{V A D M-A D M}{A D M} \times 100 \% \\
\sigma_{V D M}=\frac{V D M-D M}{D M} \times 100 \%
\end{gathered}
$$

The relative differences are plotted in Fig. $2 \mathrm{a}$ and summarized in Table $1 \mathrm{~S}$ (Supplementary Material). Average values for the whole temporal interval gives differences of $5.4 \%$ between the VADM estimation and the ADM, and 1.7\% between VDM and DM. This result confirms that the non-dipole terms are not completely cancelled after the averaging procedure. However, their contributions are lower (always below $6 \%$ for the last 110 years) than the common errors on palaeointensity estimations: around the $10 \%$ (see Donadini et al., 2009). It is also interesting to point out that all $\sigma_{\mathrm{V}(\mathrm{A}) \mathrm{DM}}$ are positive, which reflects that the $\mathrm{V}(\mathrm{A}) \mathrm{DM}$ is always higher than the (A)DM in the time span from 1900 to 2010. 
To investigate which are the most important non-dipole terms affecting the V(A)DM, we

have computed these magnitudes varying the maximum degree $N$ (from the dipole, $N=1$, up to the total field, $N=13$ ) of the harmonic expansion of the IGRF-11 model. In Fig. $2 \mathrm{~b}$ and $2 \mathrm{c}$ the temporal evolution of the $\mathrm{V}(\mathrm{A}) \mathrm{DM}$ computed from the first three field contributions (dipole, $N=1$; dipole + quadrupole, $N=2$; and dipole + quadrupole + octupole, $N=3$ ) and the total field $(N=13)$ are shown, together with the theoretical (A)DM. We can observe the well-known decrease of the dipole moment, (A)DM, during the last century. This trend is also presented in the computed $\mathrm{V}(\mathrm{A}) \mathrm{DM}$, with a decrease of $5.9 \%$ for the $\mathrm{VADM}$ and $6.4 \%$ for the VDM, calculated using all the harmonic contributions $(N=13)$. This decreasing tendency is observed in the entire time interval and does not depend on the degree $N$ considered for the analysis. The first three harmonic terms ( $N$ from 1 to 3 ) present the highest contributions to the V(A)DM estimations. When including $N=4$ and higher terms, no significant differences are observed (see Fig. 1S of the Supplementary Material).

\section{Regional effect}

In the previous section we have analysed the influence of the non-dipole contributions to the global V(A)DM estimation with synthetic data from the IGRF-11 model and using a dense grid homogeneously distributed all around the world. This kind of homogeneous database is not realistic when we are dealing with palaeomagnetic data. In this section, the objective is to study how the inhomogeneous spatial and temporal distribution of the palaeomagnetic database (Fig. 1) affects the regional averages of the $\mathrm{V}(\mathrm{A}) \mathrm{DM}_{\mathrm{i}}$.

First, we have calculated different regional averages of the $\mathrm{V}(\mathrm{A}) \mathrm{DM}_{\mathrm{i}}$ at continental scale using an homogeneous grid for each continent (denoted as $\mathrm{V}(\mathrm{A}) \mathrm{DM}_{\text {continent }}$ ). Secondly, we used the original locations of the intensity palaeomagnetic database of Genevey et al. (2008) for the 
last 3000 years and computed global estimations of the $\mathrm{V}(\mathrm{A}) \mathrm{DM}_{\mathrm{i}}$ directly $(\mathrm{V}(\mathrm{A}) \mathrm{DM}$ ) or by using

\section{a) Regional average of the $\mathrm{V}(\mathrm{A}) \mathrm{DM}_{\mathrm{i}}$ at continental scale using an homogeneous} database.

We selected 6 different spherical cap areas of $30^{\circ}$ of radius, centred in the star points of the Fig. 3, corresponding to the continental regions of North America, Europe and Northern Africa, Asia, South America, Centre and South Africa, and Oceania. In each selected area, the synthetic data were generated considering a homogeneous distribution with a density of 173 points in each spherical cap. The quantification of the regional effect (Axial Regional Effect, ARE, and Regional Effect, RE) was calculated by the relative difference between the $\mathrm{V}(\mathrm{A}) \mathrm{DM}_{\text {continent }}$ for each continent (with a sub-index indicating the name of the continent) and the theoretical values of the (A)DM as follows:

$$
\begin{gathered}
A R E=\frac{V A D M_{\text {continent }}-A D M}{A D M} \times 100 \% \\
R E=\frac{V D M_{\text {continent }}-D M}{D M} \times 100 \%
\end{gathered}
$$

To investigate the origin of the differences between the $\mathrm{V}(\mathrm{A}) \mathrm{DM}_{\text {continent }}$ and (A)DM estimations we have carried out a more detailed study of the different multipolar contributions affecting the selected regions. Apart from the $\mathrm{V}(\mathrm{A}) \mathrm{DM}_{\text {continent }}$ calculated considering the total field 
$(N=13)$, we have also computed the $\mathrm{V}(\mathrm{A}) \mathrm{DM}_{\text {continent }}$ for the total field without the quadrupole contribution, the total field without the quadrupole and octupole contributions, and using only the dipole field $(N=1)$. The ARE/RE values for all the above mentioned contributions are given in the Table 1 and along the text, and plotted in Fig. 4 along with the theoretical (A)DM.

In North America (Fig. 4a), we observe higher V(A)DM North America $_{\text {estimations than real }}$ (A)DM values, but they present a similar temporal trend. The difference between the $\mathrm{V}(\mathrm{A}) \mathrm{DM}_{\text {North America }}$ calculated from $N=1$ and $N=13$ accounts the importance of the higher nondipole terms $(N>3)$ in this region. The small difference observed between the $\mathrm{VDM}_{\text {North America }}$ and the DM is due to the octupole field that contributes around 3\% to the $\mathrm{VDM}_{\text {North America. }}$.

In Europe and Northern Africa (Fig. 4b), the main difference between regional and theoretical dipole moment estimations is the temporal evolution of these magnitudes. In contrast to the global decreasing trend of the $(A) D M$, the $\mathrm{V}(\mathrm{A}) \mathrm{DM}_{\text {Europe }}$ curves present an increasing trend with a minimum around 1930. As it can be observed in Fig. 4b, these anomalous values are related to the local effect of the quadrupole (with contributions around $-9.8 \%$ for the $\mathrm{VADM}_{\text {Europe }}$ and $-2.3 \%$ for the $\left.\mathrm{VDM}_{\text {Europe }}\right)$ and octupole terms $\left(4.4 \%\right.$ for the $\mathrm{VADM}_{\text {Europe }}, 5.5 \%$ for the $\mathrm{VDM}_{\text {Europe }}$ ), because the increasing trend disappears when removing these contributions.

In Asia (Fig. 4c), the $\mathrm{V}(\mathrm{A}) \mathrm{DM}_{\mathrm{Asia}}$ estimations are higher than the (A)DM values. A nearly constant or slightly increasing temporal trend of the virtual dipole moment is suggested by the regional averages, with a small relative maximum around 1960. The quadrupole is the main source of differences between regional and theoretical values with a percentage of contribution of $14.2 \%$ for the $\mathrm{VADM}_{\text {Asia }}$ and $11.1 \%$ for the $\mathrm{VDM}_{\text {Asia }}$.

The continent with lower $\mathrm{V}(\mathrm{A}) \mathrm{DM}_{\text {continent }}$ values than the (A)DM is South America (Fig. 4d). Here, deviations between regional averages and (A)DM estimations are greater than $19 \%$ for the $\mathrm{VADM}_{\text {South America }}$ and $15 \%$ for the $\mathrm{VDM}_{\text {South America. }}$. This area is under the influence of the 
South Atlantic Anomaly (SAA) with intensity values lower than expected for that region. The difference between the $\mathrm{V}(\mathrm{A}) \mathrm{DM}_{\text {South America }}$ and the (A)DM is mainly due to the quadrupole term ($16.2 \%$ for the $\mathrm{VADM}_{\text {South America, }}-14.8 \%$ for the $\left.\mathrm{VDM}_{\text {South America }}\right)$. The contribution of the octupole term affects around the $5.5 \%$ to the $\mathrm{VADM}_{\text {South America }}$ and $3.5 \%$ to the $\mathrm{VDM}_{\text {South America }}$ ). In this case, the quadrupole and octupole terms act in opposite direction. The first one decreases the value of $\mathrm{V}(\mathrm{A}) \mathrm{DM}_{\mathrm{S} \text { outh America, }}$ whereas the second one increases it, being the most powerful the quadrupole term.

In Africa (Fig. 4e), the most important non-dipole term is the quadrupole, with a contribution of the $-8.0 \%$ and $-9.5 \%$ for $\mathrm{VADM}_{\text {Africa }}$ and $\mathrm{VDM}_{\text {Africa }}$ respectively. However, the $\mathrm{V}(\mathrm{A}) \mathrm{DM}_{\mathrm{Africa}}$ and (A)DM estimations are similar, consequently the non-dipole contribution in the regional effect is not so strong.

Finally, Oceania is the region where the geomagnetic field is more affected by the nondipole terms (Fig. 4f). Here the V(A)DM $\mathrm{Oceania}_{\text {in }}$ reaches the highest values (up to $10.5 \cdot 10^{22} \mathrm{Am}^{2}$ for the $\operatorname{VADM}_{\text {Oceania }}$ and $9.5 \cdot 10^{22} \mathrm{Am}^{2}$ for the $\left.\mathrm{VDM}_{\text {Oceania }}\right)$, associated with the quadrupole $(18.2 \%$ for the $\mathrm{VADM}_{\text {Oceania }}, 11.8 \%$ and for the $\left.\mathrm{VDM}_{\text {Oceania }}\right)$ and with the octupole terms $(7.3 \%$ for the $\mathrm{VADM}_{\text {Oceania }}, 8.2 \%$ and for the $\mathrm{VDM}_{\text {Occania }}$. Differences between $\mathrm{V}(\mathrm{A}) \mathrm{DM}_{\text {Ocania }}$ and $(\mathrm{A}) \mathrm{DM}$ estimations are about 35\% for the $\mathrm{VADM}_{\text {Oceania }}(\mathrm{ARE})$ and $19 \%$ for the $\mathrm{VDM}_{\text {Ocenia }}(\mathrm{RE})$.

The values contained in Table 1 shows that, in general, ARE is greater than RE, and that these errors can be locally very high. The high errors and the differences observed between $\mathrm{VADM}_{\text {continent }}$ and $\mathrm{VDM}_{\text {continent }}$ suggests that the use of mixed VADM/VDM curves, commonly combined in palaeomagnetism due to the lack of inclination values (e.g. Genevey et al., 2008), introduces an additional source of errors. Then, it is not an appropriate approach.

On the other hand, the palaeomagnetic database for the last 14000 years is clearly biased (Fig.1): for the last 8000 years the archaeomagnetic data are concentrated in Eurasia, while for the 
earlier times, from $12000 \mathrm{BC}$ to $6000 \mathrm{BC}$, the available data are mainly lava flows from Hawaii and North America. This means that if V(A)DM estimations are not adequately averaged, they might be clearly influenced by the regional effect. However, we must point out that the regional effect depends on the geomagnetic field structure and then, it is time-dependent, i.e. our values cannot be directly extrapolated to the past, but provide a reliable idea about the order of magnitude of the regional effect.

\section{b) Regional average of the $\mathrm{V}(\mathrm{A}) \mathrm{DM}_{\mathrm{i}}$ using simulations of the palaeointensity data distribution.}

One of most important problems in the ancient dipole moment estimation, in both $\mathrm{V}(\mathrm{A}) \mathrm{DM}$ and (A)DM, is the inhomogeneous palaeomagnetic database. Most of the palaeomagnetic data are concentrated in the Northern Hemisphere (around 95\% of the archaeomagnetic and lava flow data for the last 3000 years, Donadini et al., 2009). This heterogeneous spatial distribution generates problems in the $\mathrm{V}(\mathrm{A}) \mathrm{DM}$ (global average) such as an overestimation of the regions with more available data, as the case of Eurasia (Genevey et al., 2008). In order to correct this regional effect in the V(A)DM estimation, Genevey et al. (2008) proposed a simple first-order regional weighting scheme based on the definition of eight regions (rectangle regions in Fig. 3). These regions were selected taking into account the locations of the palaeointensity data compiled in the database ArcheoInt (Genevey et al., 2008) for the last 3000 years. They considered that each selected region contains enough palaeointensity information. Here, in order to check the reliability of the regional weighting scheme of Genevey (2008), we simulate their procedure but using synthetic data from the IGRF-11 model.

The data were synthesized at the locations of the ArcheoInt database (Fig. 3). Since the database contains palaeomagnetic data for the last 3000 years whereas the IGRF-11 model only 
spans from 1900 to 2010, we had to linearly adapt the time interval covered by the database to the last century. That is to say, we simulated a synthetic database with field information given by the IGRF-11 model at the locations of the ArcheoInt database (sites represented in Fig. 3) and we attributed to each data a fictitious age (linearly adapted) within the 1900 to 2010 time interval. That is to say, the assigned age has been estimated as follows: $t_{2}=m \cdot\left(1000+t_{1}\right)+1900$, being $\mathrm{m}=110 / 2900, \mathrm{t}_{2}$ the time adapted in the new synthetic database and $t_{1}$ the time given by the ArcheoInt database.

Two important points to remark: 1) we used all the locations of the ArcheoInt database. That is, we did not introduce the selection criteria used by Genevey et al. (2008) to consider only high quality palaeointensity data. 2) We have synthesized both inclination and intensity data at all locations. However, some of the data of ArcheoInt provide only intensity values without inclination data (the $58 \%$ of the intensity data) and, therefore, the $\mathrm{VDM}_{\mathrm{i}}$ could not be always calculated. This is the reason why the authors used a mixed VADM/VDM curves. Consequently, we are considering the best case scenario (i.e., lower errors are expected) for the regional averaging procedure proposed by Genevey et al. (2008).

The regional weighting scheme of Genevey et al. (2008), consists on calculating eight regional VADM and VADM/VDM curves for each selected region, by using the classical sliding overlapping windows technique, and then computing the averaged global VADM and VADM/VDM curves (assuming equal weight for each region).

To estimate the temporal evolution of the $\mathrm{V}(\mathrm{A}) \mathrm{DM}_{\text {regional }}$ we have transformed the original 500 -yr window shifted by 250 and 200 -yr window shifted by 100 years into 20 -yr window shifted by $10 \mathrm{yr}$ and $10-\mathrm{yr}$ window shifted by 5 year, respectively. We calculated the regional average $\mathrm{V}(\mathrm{A}) \mathrm{DM}_{\text {regional }}$ from each region and time window and then, an estimation of the global weighted averaged $\mathrm{V}(\mathrm{A}) \mathrm{DM}$, denoted as $\mathrm{V}(\mathrm{A}) \mathrm{DM}_{\mathrm{W}}$, was obtained. The different $\mathrm{V}(\mathrm{A}) \mathrm{DM}_{\text {regional }}$ for each 
region are plotted in the supplementary Fig. $2 \mathrm{~S}$ and the global $\mathrm{V}(\mathrm{A}) \mathrm{DM}_{W}$ is plotted in the Fig. 5 . For comparison, we have also added the global V(A)DM directly calculated from all data, without the regional weighting procedure. The theoretical (A)DM curves are represented as well.

In order to provide a more realistic result, we have perturbed our synthetic database using a set of 500 random perturbations obtained from Gaussian distributions with mean values equal to zero and standard deviations equal to the standard deviation of the archaeomagnetic data for the last 3000 years ( $4.2^{\circ}$ for inclinations and $8.6 \mu \mathrm{T}$ for intensities, Donadini et al., 2009). We have repeated the previous process using the new datasets of perturbed data. The results provide the bands at $\sim 65 \%$ of confidence level (dashed lines in Fig. 5) for the $\mathrm{V}(\mathrm{A}) \mathrm{DM}_{\mathrm{W}}$ and for the global V(A)DM (without the regional weighting scheme).

Our results indicate that the variability reported is related to the spatial and temporal distribution of the data. The data distribution is more different among shorter windows, leading to differences in influence of regional bias from one window to the next. The higher variability is an artefact of the regional effect varying with the data distribution.

The VADM presents an increasing temporal trend, with a maximum value around 1970 which is a clear artefact. An increasing trend was also observed in the $\operatorname{VADM}_{\text {Europe }}$ curve for the European continent in our previous study (see Fig. 4b). This means that when VADM is obtained from global averaging, the European zone is overestimated because it is the region with more available data (up to 55\%, regions 1 and 2 in the Fig. 3). So, when the regional weighting scheme is applied, the influence of European data is weakened and the VADM evolution is more similar to the ADM trend. Although still higher $\mathrm{VADM}_{\mathbb{W}}$ values than $\mathrm{ADM}$ are obtained, that means that the regional effect has not been completely cancelled. Deviations between the global $\mathrm{V}(\mathrm{A}) \mathrm{DM}_{W} / \mathrm{V}(\mathrm{A}) \mathrm{DM}$ and the (A)DM are outlined in the Table 2. Lower relative errors between $\mathrm{V}(\mathrm{A}) \mathrm{DM}$ and (A)DM than between $\mathrm{V}(\mathrm{A}) \mathrm{DM}_{\mathrm{W}}$ and (A)DM are obtained. However, this result 
does not mean that the use of the regional weighting scheme is unappropriated. As we discussed previously, the results are more consistent with the theoretical trend when a regional weighting is considered.

The lower differences between $\mathrm{VDM}_{W}$ and VDM trends and the lower errors in relation with DM values (see Table 2), are related to the use of more field information: the inclination in addition to the intensity. With this additional information changes in the tilt of the dipole are also considered and, therefore, a more accurate description of the dipole moment is expected. It is important to note that the original ArcheoInt database contains inclination information of around $48 \%$ of the sites. Consequently the errors that we have obtained are the lowest that could be reached.

Finally, we would like to point out that the error bands of the V(A)DM are narrower than those of the $\mathrm{V}(\mathrm{A}) \mathrm{DM}_{\mathrm{W}}$. The reason is the average procedure: the $\mathrm{V}(\mathrm{A}) \mathrm{DM}$ is obtained with all the data and this high number of data give lower standard deviations. This is not the case of the $\mathrm{V}(\mathrm{A}) \mathrm{DM}_{\mathrm{W}}$, where the lower number of regions to be averaged (8 regions) increases the standard deviations.

\section{Regional Indirect effect}

In this section, we want to analyse the influence of a sparse database in the models generated from palaeomagnetic/archaeomagnetic data (e.g. Korte et al., 2009, 2011; Korte and Constable, 2011; Licht et al., 2013; Pavón-Carrasco et al., 2014) and, specially, its effects on the (A)DM estimation.

We have developed a geomagnetic global model by using the same synthetic database of the previous Section 3b, including a new set of synthetic data for the declination, which is 
necessary to develop the global model. The global model, called IGRF-11 $1_{\mathrm{S}}$, was obtained by using the classical approach from palaeomagnetic data (Korte and Constable, 2005): the Spherical Harmonic Analysis (SHA) technique in space and the penalized cubic B-splines (De Boor, 2001) in time. In terms of the SHA, the potential of the internal geomagnetic field can be established at any point $(r, \theta, \lambda)$ over the Earth's surface as (1). The usual time-dependent Gauss coefficients $\left(g_{n}^{m}(t)\right.$ and $\left.h_{n}^{m}(t)\right)$ may be developed using penalized cubic B-splines defined by the matrix $B_{q}(t)$, as follows:

$$
\begin{aligned}
& g_{n}^{m}(t)=\sum_{q=1}^{Q} g_{n, q}^{m} B_{q}(t) \\
& h_{n}^{m}(t)=\sum_{q=1}^{Q} h_{n, q}^{m} B_{q}(t)
\end{aligned}
$$

where $Q$ is the maximum degree of the temporal expansion and $g_{n, q}^{m}(t)$ and $h_{n, q}^{m}(t)$ are the timedependent spherical harmonic coefficients.

In palaeomagnetic studies, the measures of the geomagnetic field are $D, I$ and $F$. These components cannot be expressed as a linear combination of the Gauss coefficients. For this reason, any scalar element of the geomagnetic field $d$ (declination, inclination or intensity) must be given as a non-linear function $f$, related to Eq. 1, and depending on the time-dependent Gauss coefficients:

$$
\mathrm{d}=\mathrm{f}(\overrightarrow{\mathrm{m}})+\varepsilon
$$

where $\vec{m}$ contains all the Gauss coefficients and $\varepsilon$ is the error. To find the optimal set of timedependent Gauss coefficients, we chose the regularized least square inversion applying the Newton-Raphson iterative approach (Gubbins and Bloxham, 1985): 
$\overrightarrow{\mathrm{m}}_{\mathrm{i}+1}=\overrightarrow{\mathrm{m}}_{\mathrm{i}}+\left(\widehat{\mathrm{A}}_{\mathrm{i}}^{\prime} \cdot \widehat{\mathrm{A}}_{\mathrm{i}}+a \cdot \hat{S}+\tau \cdot \widehat{T}\right)^{-1} \times\left(\widehat{\mathrm{A}}_{\mathrm{i}}^{\prime} \cdot \overrightarrow{\mathrm{r}}_{\mathrm{i}}-\alpha \cdot \widehat{\mathrm{S}} \cdot \overrightarrow{\mathrm{m}}_{\mathrm{i}}-\tau \cdot \widehat{\mathrm{T}} \cdot \overrightarrow{\mathrm{m}}_{\mathrm{i}}\right)$

Where $\hat{A}$ is the matrix of parameters which depends on the $\mathrm{SH}$ functions in space and time (the so called Frechet matrix) and $\hat{A}^{\prime}$ is the transpose of $\hat{A} . \vec{\gamma}$ is the vector of differences between the input data and modelled data for the $i^{\text {th }}$ iteration. The $\hat{S}$ and $\hat{T}$ matrices are the spatial and temporal regularization matrices, respectively, with damping parameters $\alpha$ and $\tau$. The index $i$ indicates the number of the iteration, which requires a first initial solution $\vec{m}_{0}$. To create the Bspline base we have selected knots points between 1899 and 2011 every 4 years.

The spatial regularization minimizes the Ohmic dissipation at the core-mantle boundary (Gubbins, 1975), which can be written as:

$\hat{S}=\frac{4 \pi}{t_{e}-t_{s}} \int_{t_{s}}^{t_{e}} \sum_{n=1}^{N} \frac{(n+1)(2 n+1)(2 n+3)}{n}\left(\frac{a}{c}\right)^{2 n+3} \sum_{m=0}^{n}\left[\left(g_{n}^{m}(t)\right)^{2}+\left(h_{n}^{m}(t)\right)^{2}\right] d t$

where $t_{s}$ and $t_{e}$ are the initial and final epoch respectively and $c$ is the mean radius of the coremantle boundary $(\mathrm{CMB})$. The temporal regularization minimizes the second time derivative of the radial field at the CMB (Bloxham and Jackson, 1992), as follows:

$$
\widehat{T}=\frac{1}{t_{e}-t_{s}} \int_{t_{s}}^{t_{e}} \oint_{\Omega}\left(\partial_{t}^{2} B_{r}\right)_{r=c}^{2} d \Omega d t
$$

where $\mathrm{d} \Omega$ is the differential solid angle over the sphere $\Omega$. The choice of the best regularization is applied to obtain a model with the minimal complexity and a reasonable fit to the data. After carrying out several tests with different values of damping parameters (e.g. Licht et al., 2013; Pavón-Carrasco et al., 2014), we have chosen $\alpha$ and $\tau$ equal to $5 \cdot 10^{-9} \mu \mathrm{T}^{-2}$ and $10^{-3} \mu \mathrm{T}^{-2} \mathrm{yr}^{4}$, respectively. Again, in order to provide a more realistic result, we have also used the 500 perturbed dataset of the previous section. In this case, the new element (the declination) was 
perturbed by a Gaussian distribution with mean $0^{\circ}$ and standard deviation equal to $6.1^{\circ}$ (from Donadini et al., 2009). A total of 500 models were developed providing the error modelling as the standard deviation of the Gauss coefficients.

The IGRF-11 $\mathrm{S}$ model is compared with the original IGRF-11. In Fig. 6 the maps of $D, I$, $F$ at 1955 (central epoch of the considered time interval: 1900 - 2010) from the IGRF-11 and IGRF-11 models are represented. The differences between these geomagnetic elements are also represented, together with the locations of the data in the time span from 1950 to 1960 (the three knot points considered for 1955). These data represent less than $10 \%$ of the total data. We can observe that the IGRF-11 S reproduces very well the main characteristics of the geomagnetic field (see also the maps provided in the Supplementary Material). It is highlighted the good representation of the Southern Atlantic Anomaly by the IGRF-11 s model, in spite of few information available from this region (and from the Southern Hemisphere in general).

The major differences between both models are located in the regions with absence of data: Africa and Antarctica. The highest differences in declination are found in Antarctica and the Southern Indian Ocean. Discrepancies in inclination are low, with the exception of a small dipole in central Southern Africa that produces inclination differences up to $8^{\circ}$ and $-10^{\circ}$. The major disagreement in intensity is observed in Southern Africa and Southern Atlantic Ocean, with higher intensities than the IGRF model (around $12 \mu \mathrm{T}$ ). These artefacts are due to the absence of information to reproduce adequately the SAA, i.e. the main differences between the IGRF-11 and the IGRF-11 are located in the region affected by the SAA from where not enough palaeomagnetic information is available.

Finally and using the new set of Gauss coefficients provided by the IGRF-11 s model, we have calculated the (A)DM curves, denoted as (A)DM $\mathrm{DM}_{\mathrm{S}}$. The coefficients' error is used to obtain the error bands at $\sim 65 \%$ of confidence level. Fig. 7 shows the $(A) D_{S}$ curves together with the 
(A)DM curves of the original IGRF-11 model and the Table 3 summarizes the relative errors between them. We can observe a similar temporal trend between all (A)DM, with lower values at the beginning of the time interval, and higher values at the end, likely due to the inhomogeneous data distribution. In spite of this fact, we can observe that when we consider the error band, the theoretical (A)DM lie into the error band.

In contrast to the regional weighting scheme, where artificial variations of the dipole moment were obtained for small sliding windows, dipole variations obtained by modelling reproduces much better the theoretical dipole moment. But we have to take into account that we have used synthetic data, i.e. we have considered the best situation. And more importantly, in this last case we have increased the number of palaeomagnetic information (including declinations) with respect to the previous section. From this analysis we could conclude that when directional palaeomagnetic information is available, the best method to compute the geomagnetic dipole moment evolution is from global modelling.

\section{Conclusions.}

In this work, we have evaluated and quantified different sources of error introduced in the geomagnetic dipole moment estimation. The principal errors considered in this study come from 1) the averaged procedure of the non-dipole contribution, because palaeomagnetic data record all the contributions of the geomagnetic field and not only the dipole field (non-dipole effect); and 2) the effect of the current palaeomagnetic database distribution in the averaged procedure (regional effect) and in the generation of the global geomagnetic field models (regional indirect effect). To evaluate these errors we have used the IGRF-11 model. 
Firstly, we have estimated the non-dipole effect in the global and regional averages for the last

century. Although the main assumption is that the non-dipole terms are cancelled in the averaged procedure, we have reported that this contribution is not cancelled completely. In the global averages, it can reach the $5.8 \%$ for the VADM and the $2.3 \%$ for the VDM. The most important terms are the quadrupole and octupole. For the last 110 years, the non-dipole effect is small (never greater 6\%) if we compare with the values of the palaeointensity errors (around 10\%).

In the regional averages, the non-dipole effect can give rise to deviations between the V(A)DM and (A)DM higher than 35\% in some continental regions, such as Oceania. Again, the quadrupole and octupole terms are the most important non-dipolarity sources, being especially important the quadrupole effect associated with the Southern Atlantic Anomaly. This term produces a decrease of about $15-16 \%$ in the $\mathrm{V}(\mathrm{A}) \mathrm{DM}_{\text {continent }}$ over the Southern American region. Another interesting artefact is the anomalous evolution trend of $\mathrm{V}(\mathrm{A}) \mathrm{DM}_{\text {continent }}$ observed in Europe and Asia. The $\mathrm{V}(\mathrm{A}) \mathrm{DM}_{\text {Europe }}$ and $\mathrm{V}(\mathrm{A}) \mathrm{DM}_{\text {Asia }}$ are increasing whereas (A)DM is decreasing for the time span from 1900 to 2010.

Due to the sparse palaeomagnetic database, clearly biased towards the European region (with more available data), the regional evolution of the $\mathrm{V}(\mathrm{A}) \mathrm{DM}_{\text {Europe }}$ could affect to the global averages. One of the methods proposed to avoid this overestimation is the first-order regional weighting scheme proposed by Genevey et al. (2008). Our results confirm the improvement of the $\mathrm{V}(\mathrm{A}) \mathrm{DM}$ when the regional weighting scheme is considered, with respect to the global averaged on the total database. However, mathematical artefacts are created with this procedure depending on the size of the temporal sliding windows used and the number of data available. The smaller temporal sliding window is, the more artefacts appear. This varying regional bias effect might also affect to the power distribution between dipole and non-dipole contributions in palaeomagnetic SHA models. 
Finally, we have analyzed the effect of the current data distribution for the last 3000 years on the generation of the global geomagnetic field models. We have generated a synthetic model (IGRF-11 $1_{\mathrm{S}}$ ) with the $D, I, F$ synthesized in the locations of the ArcheoInt database with the temporal interval adapted linearly to the last century. The results confirm that the main differences between the model created and the IGRF-11 are located in regions with lack of data (e.g. Africa). Moreover, we can observe a well agreement between the (A)DM calculated from the IGRF-11 S and the IGRF-11 models, lying into the error band with a confidence level of $\sim 65 \%$.

From this analysis we might conclude that when directional and intensity palaeomagnetic information is available, in spite of the inhomogeneity of the database, the best method to compute the geomagnetic dipole moment evolution is from global modelling. The (A)DM $\mathrm{M}_{\text {model }}$ seems to be the most appropriate parameter to correct the cosmogenic isotopes production or to study the possible correlations between the geomagnetic field and the climate.

\section{Acknowledgements.}

The authors are grateful to the Spanish research project CGL2011-24790 of the Spanish Ministerio de Economía y Competitividad and the FPI grant BES-2012-052991, which has allowed to the author S.A. Campuzano a stay for 3 months at INGV in Rome. All algorithms have been developed in Matlab $^{\circledR}$ codec (Matlab 7.11.0, R2010b) along with the figures. The authors also thank two anonymous reviewers for the constructive comments and suggestions which have helped to improve substantially this manuscript.

\section{References.}


Christensen, U.R., Aubert, J., Hulot, G. (2010), Conditions for Earth-like geodynamo models. Earth Planet. Sci. Lett. 296 (3-4), 487-496.

De Boor, C., A Practical Guide to Splines (Springer, New York 2001).

Donadini, F., Korte, M., Constable, C. G. (2009), Geomagnetic field for 0-3 ka: 1. New data sets for global modeling. Geochem. Geophys. Geosyst. 10 (6), Q06007.

Finlay, C. C., et al. (2010), International Geomagnetic Reference Field: the eleventh generation. Geophys. J. Int. 183, 1216-1230.

Gallet, Y., Genevet, A., Fluteau, F. (2005), Are there connections between the Earth's magnetic field and climate? Earth Planet. Sci. Lett. 236, 339-347.

Gauss, C.F., Intensitas vis Magneticae Terrestris ad Mensuram Absolutam Revocata (Dieterich, Göttingen 1833).

Genevey, A., Gallet, Y., Constable, C., Korte, M., Hulot, G. (2008), ArcheoInt: An upgraded compilation of geomagnetic field intensity data for the past ten millennia and its application to the recovery of the past dipole moment. Geochem. Geophys. Geosyst. 9 (4), Q04038.

Genevey, A., Gallet, Y., Thébault, E., Jasset, S., Le Goff, M. (2013), Geomagnetic field intensity variations in Western Europe over the past 1100 years. Geochem. Geophys. Geosyst. 14 (8), 2858-2872.

Glatzmaier, G.A., Roberts, P.H. (1995). A three-dimensional self-consistent computer simulation of a geomagnetic field reversal. Nature. 377, 203-209.

Gubbins, D. (1975), Can the Earth's magnetic field be sustained by core oscillations? Geophys. Res. Lett. 2, 409-412.

Gubbins, D. (1987), Mechanism for geomagnetic polarity reversals. Nature. 326, 167-169. 
Gubbins, D., and Bloxham, J. (1985), Geomagnetic field analysis. III. Magnetic fields on the coremantle boundary. Geophys. J. R. Astron. Soc. 80, 695-713.

Jackson, A., Jonkers, A.R.T., Walker, M.R. (2000), Four centuries of geomagnetic secular variation from historical records. Philos. Trans. R. Soc. Lond. A 358 (1768), 957-990.

Jacobs, J. A., Geomagnetism (Vol. 1) (Academic Press 1991).

Jonkers, A. R. T., Jackson, A., Murray, A. (2003), Four centuries of geomagnetic data from historical records, Rev. Geophys. 41(2), 1006.

Korte, M., and Constable, C.G. (2003), Continuous geomagnetic field models for the past 3000 years. Phys. Earth Planet. Interiors. 140, 73-89.

Korte, M., and Constable, C.G. (2005a), Continuous geomagnetic field models for the past 7 millennia: 2 CALS7K. Geochem. Geophys. Geosyst. 6, Q02H16.

Korte, M., and Constable, C.G. (2005b), The geomagnetic dipole moment over the last 7000 years—new results from a global model. Earth Planet. Sci. Lett. 236, 348- 358.

Korte, M., and Constable, C.G. (2011), Improving geomagnetic field reconstructions for 0-3 ka. Phys. Earth Planet. Interiors. 188, 247-259.

Korte, M., Genevey, A., Constable, C.G., Frank, U., Schnepp, E. (2005), Continuous geomagnetic field models for the past 7 millennia: A new global data compilation. Geochem. Geophys. Geosyst. 6, Q02H15.

Korte, M., Donadini, C., Constable, C.G. (2009), The geomagnetic field for 0-3 ka, part II: a new series of time-varying global models. Geochem. Geophys. Geosyst. 10, Q06008. 
Kovacheva, M., Boyadziev, Y., Kostadinova, M., Jordanova, N., Donadini, F. (2009), Updated archeomagnetic data set of the past 8 millennia from the Sofia laboratory, Bulgaria, Geochem. Geophys. Geosyst., 10, Q05002, doi:10.1029/2008GC002347.

Licht, A., Hulot G., Gallet Y., Thébault E. (2013), Ensembles of low degree archeomagnetic field models for the past three millennia. Phys. Earth Planet. Interiors. 224, 38-67.

Macouin, M., Valet, J.P., Besse, J. (2004), Long-term evolution of the geomagnetic dipole moment, Phys. Earth Planet. Interiors. 147, 239-246.

Muscheler, R., Joos, F., Beer, J., Muller, S.A., Vonmoos, M., Snowball, I. (2007), Solar activity during the last $1000 \mathrm{yr}$ inferred from radionuclide records. Quatern. Sci. Rev. 26, 82-97.

Pavón-Carrasco, F.J., Osete, M.L., Torta, J.M., De Santis, A. (2014), A geomagnetic field model for the Holocene based on archaeomagnetic and lava flow data. Earth Planet. Sci. Lett. 388, 98-109.

Roth, R., and Joos, F. (2013), A reconstruction of radiocarbon production and total solar irradiance from the Holocene $14 \mathrm{C}$ and CO2 records: implications of data and model uncertainties, Clim. Past Discuss. 9, 1165-1235.

Tauxe, L. (1993), Sedimentary records of relative paleointensity of the geomagnetic field: theory and practice. Rev. Geophys. 31, 319-354.

Usoskin, I., Korte, M., Kovaltsov, G.A. (2008), Role of centennial geomagnetic changes in local atmospheric ionization. Geophys. Res. Lett. 35, L05811.

Vieira, L.E.A., Solanki, S.K., Krivova, N.A., Usoskin, I.G. (2011), Evolution of the solar irradiance during the Holocene. Astron. Astrophys. 531, A6. 
Whaler, K. A. \& Gubbins, D. (1981), Spherical harmonic analysis of the geomagnetic field: an example of a linear inverse problem, Geophys. J. R. astr. SOC., 65, 645-693.

Yang S., Odah, H., Shaw, J. (2000), Variations in the geomagnetic dipole moment over the last 12000 years. Geophys. J. Int. 140 (1), 158-162.

\section{Figure captions.}

Figure 1. Spatial (a)-(c) and temporal (d)-(f) distribution of the archaeomagnetic and lava flow data for the last 14000 years. Adapted from Pavón-Carrasco et al. (2014).

Figure 2. (a) Relative errors between VADM and ADM $\left(\sigma_{V A D M}\right)$ and VDM and DM $\left(\sigma_{V D M}\right)$ calculated from Eqs. 6 and 7. Temporal evolution of the (b) VADM and (c) VDM curves obtained with synthetic data of the IGRF-11 model, for $N=1$ (solid blue), $N=2$ (solid green), $N=3$ (solid red) and $N=13$ (solid black), together with the (A)DM curves represented with crosses, by comparison.

Figure 3. Map showing considered continental areas in the study of regional effect. The spherical caps (green circles) are of $30^{\circ}$ of radius, and are centred in the yellow stars. The geographical distribution of the ArcheoInt database (Genevey et al., 2008) for the last 3000 years are also shown (black and grey points). Definition of the eight regions (each $30^{\circ}$ width both in latitude and longitude) chosen for the next VADM and VDM computations as Genevey et al. (2008): 1, western Europe (latitudes between 30N and 60N, longitudes between 10W and 20E); 2, central Europe and Near East (latitudes between $30 \mathrm{~N}$ and $60 \mathrm{~N}$, longitudes between $20 \mathrm{E}$ and 50E); 3, central Asia (latitudes between $12 \mathrm{~N}$ and $42 \mathrm{~N}$, longitudes between 55E and 85E); 4, eastern Eurasia (China; latitudes between 20N and 50N, longitudes between 95E and 125E); 5, Far East (Japan; latitudes between 20N and 50N, longitudes between 127E and 157E); 6, Pacific 
(Hawaii; latitudes between 5N and 35N, longitudes between 190E and 220E); 7, southwest part northwest part of South America (Peru; latitudes<0, longitudes between 270E and 300E).

Figure 4. Regional averaged of VADM (left column) and VDM (right column) (V(A)DM continent curves, synthesized from IGRF-11 model to $N=13$ (solid black), $N=13$ minus quadrupole term (solid green), $N=13$ minus quadrupole and octupole terms (solid red) and $N=1$ (solid blue) in (a) North America, (b) Europe and Northern Africa, (c) Asia, (d) South America, (e) Centre and South Africa, (f) Oceania. The ADM and DM curves (crosses) are shown for comparison.

Figure 5. Effect of the geographic bias in the distribution of the synthetic data on the estimates of the (left) global VADM and (right) global VDM variation curves. Computations are performed using the selected data (see Fig. 3) smoothed over overlapping sliding windows of (a) 20 years shifted by 10 years, (b) 10 years shifted by 5 years and (c) 5 years shifted by 2.5 years. Solid blue, $\mathrm{V}(\mathrm{A}) \mathrm{DM}_{\mathbb{W}}$ computed with the weighting scheme of Genevey et al. (2008); solid red, V(A)DM calculated from all data with the regional weighting scheme; dashed lines show the error band with a level of confidence of $65 \%$, computed as the involving of 500 perturbed databases (see text for more details); crosses, (A)DM calculated from the first three Gauss coefficients.

Figure 6. Declination, $D$, inclination, $I$, and intensity, F, maps at 1955 for (a) global model generated using synthetic data from ArcheoInt IGRF-11 (b) IGRF-11 model. Maps for different years are given as Supplementary Material. (c) Residual between both models is also shown.

Figure 7. For IGRF-11 $\left(\right.$ a) $\mathrm{ADM}_{\mathrm{S}}$ and (b) $\mathrm{DM}_{\mathrm{S}}$ curves together with the error band at $\sim 65 \%$ of confidence level are shown. The theoretical (A)DM is also plotted, for comparison.

\section{Tables.}


Table 1. Errors (rms) of $\mathrm{V}(\mathrm{A}) \mathrm{DM}_{\text {continental }}$ estimations for the period of 1900-2010. The (axial) regional effect, (A)RE, are computed from Eqs. 8 and 9.

Table 2. Errors (rms) of regionally weighting averaged $\mathrm{V}(\mathrm{A}) \mathrm{DM}\left(\mathrm{V}(\mathrm{A}) \mathrm{DM}_{\mathrm{W}}\right)$ estimations for the period of 1900-2010 and the $\mathrm{V}(\mathrm{A}) \mathrm{DM}$ without regional weighting scheme, together with the error band (confidence level of $\sim 65 \%$ ). The comparisons are developed in function on (A)DM for the same temporal interval.

Table 3. Errors (rms) for the deviation between $\mathrm{ADM}$ and $\mathrm{DM}$ of the geomagnetic field calculated with the Gauss coefficients of IGRF-11 s and IGRF-11 models from 1900 to 2010, every 5 years, together with the error band (confidence level of $\sim 65 \%$ ).

\section{Figure captions (Supplementary material).}

Figure 1S. (a) VADM and (b) VDM curves computed for increasing maximum degree $N$ from synthetic data of IGRF-11 model in a global and homogeneous grid on the Earth.

Figure 2S. VADM (left) and VDM (right) regional variation curves in the different rectangular regions of the Fig. 3 (see colour code in the legend, following to Fig. 10 from Genevey et al., 2008) obtained with the help of sliding windows of (a) 20 years shifted by 10 years and (b) 10 years shifted by 5 years. All curves have been obtained from the synthetic database in the locations given in the Fig. 3 .

Figure 3S. Snapshots of (left to right) declination, $D$, inclination, $I$, and intensity, $F$, maps for global model generated using synthetic data from ArcheoInt IGRF-11 $\mathrm{S}$ and their corresponding residual respect to the IGRF-11 model, from 1900 to 2010, every 10 years. 
Table captions (Supplementary material).

1

2

Table 1S. Non-dipole effect. Deviations between the VADM and ADM $\left(\sigma_{\mathrm{VADM}}\right)$ and the VDM and DM $\left(\sigma_{\mathrm{VDM}}\right)$ calculated from Eqs. 6 and 7 for the time span from 1900 to 2010, every 5 years (from synthetic data generated by the IGRF-11). See Fig. 2a and text for more details. The last row shows the arithmetic mean for both deviations in the all interval. 


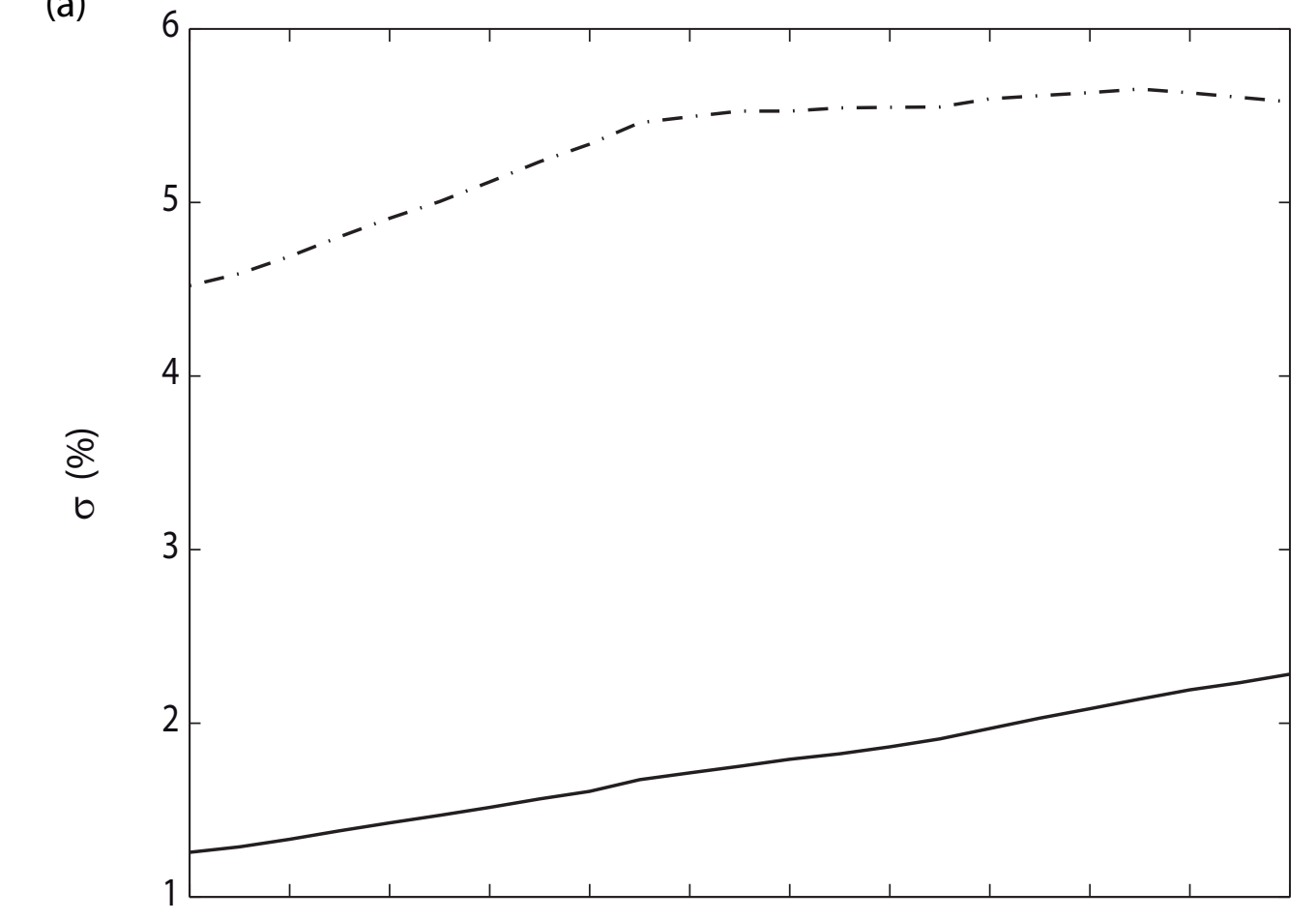

$1900 \quad 1910 \quad 1920 \quad 1930 \quad 19401950 \quad 1960 \quad 1970 \quad 1980 \quad 1990 \quad 2000 \quad 2010$ Time (yrs) (b)

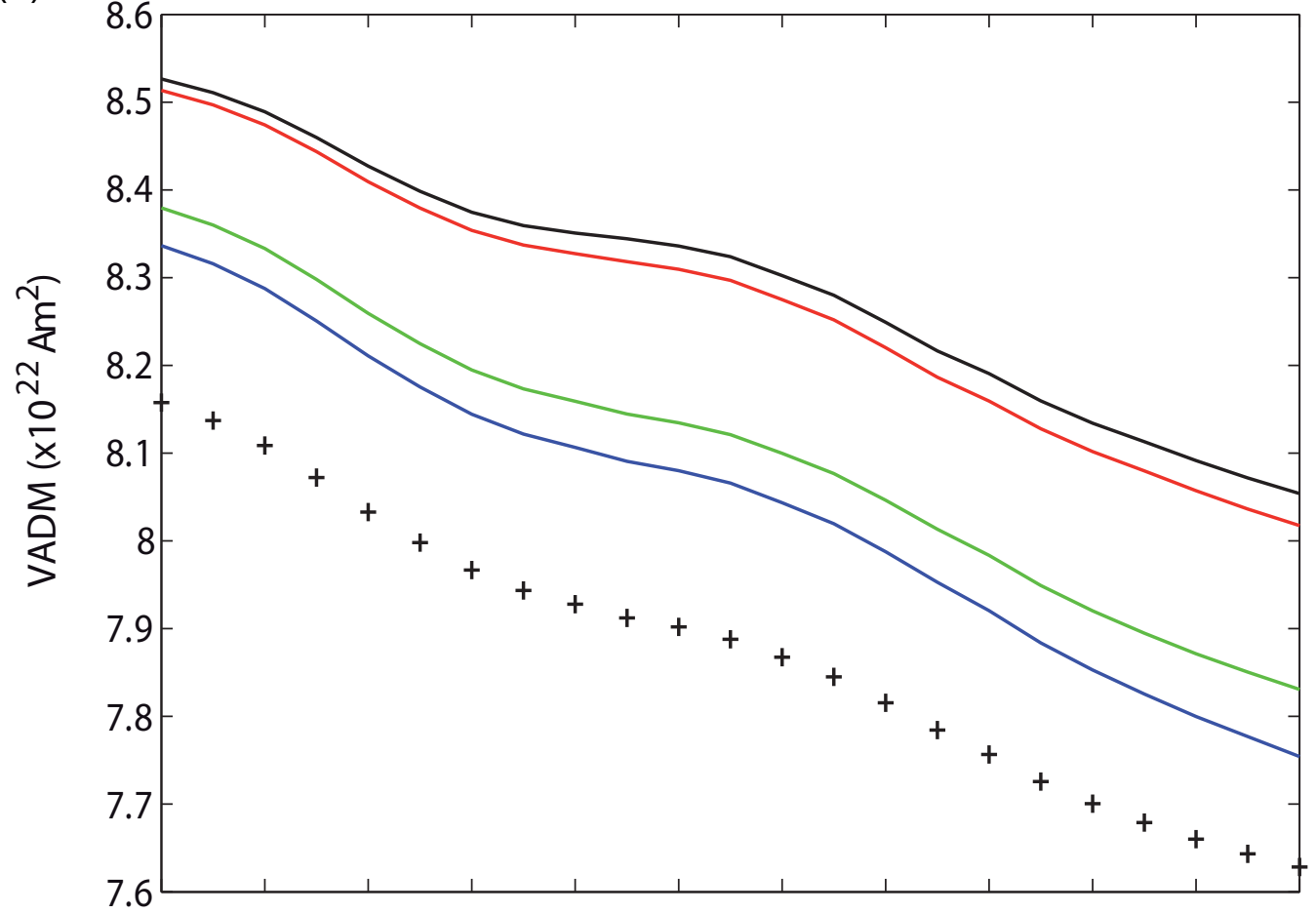

$1900 \quad 1910192019301940195019601970 \quad 19801990 \quad 2000 \quad 2010$ Time (yrs)

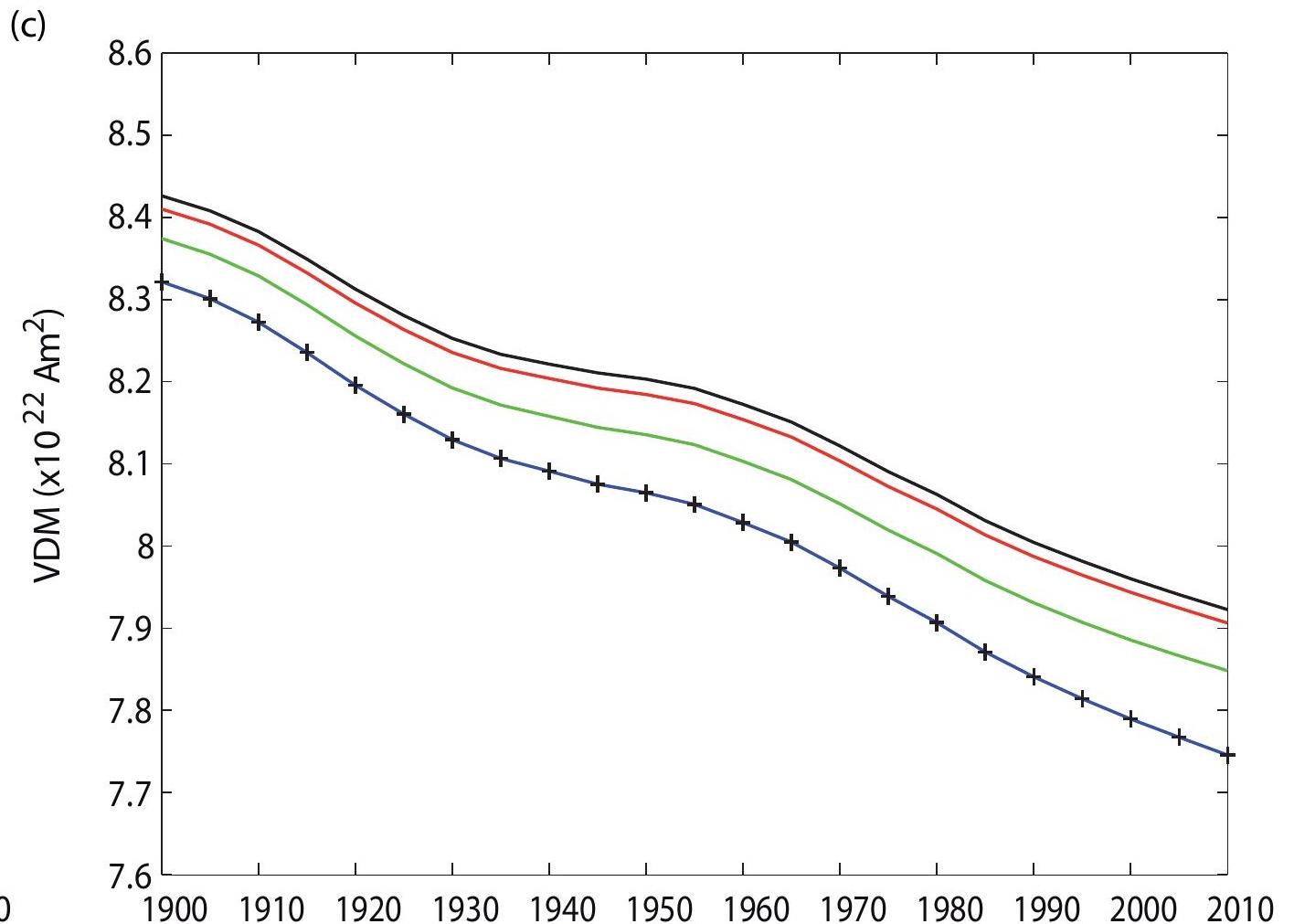

$\begin{array}{llllllllllll}7.6 & 1900 & 1 & 1 & 1 & 1 & 1 & 1 & 1 & 1 & 1 & 1 \\ 1920 & 1930 & 1940 & 1950 & 1960 & 1970 & 1980 & 1990 & 2000 & 2010\end{array}$ Time (yrs) 


\section{Figure3}

Click here to 98

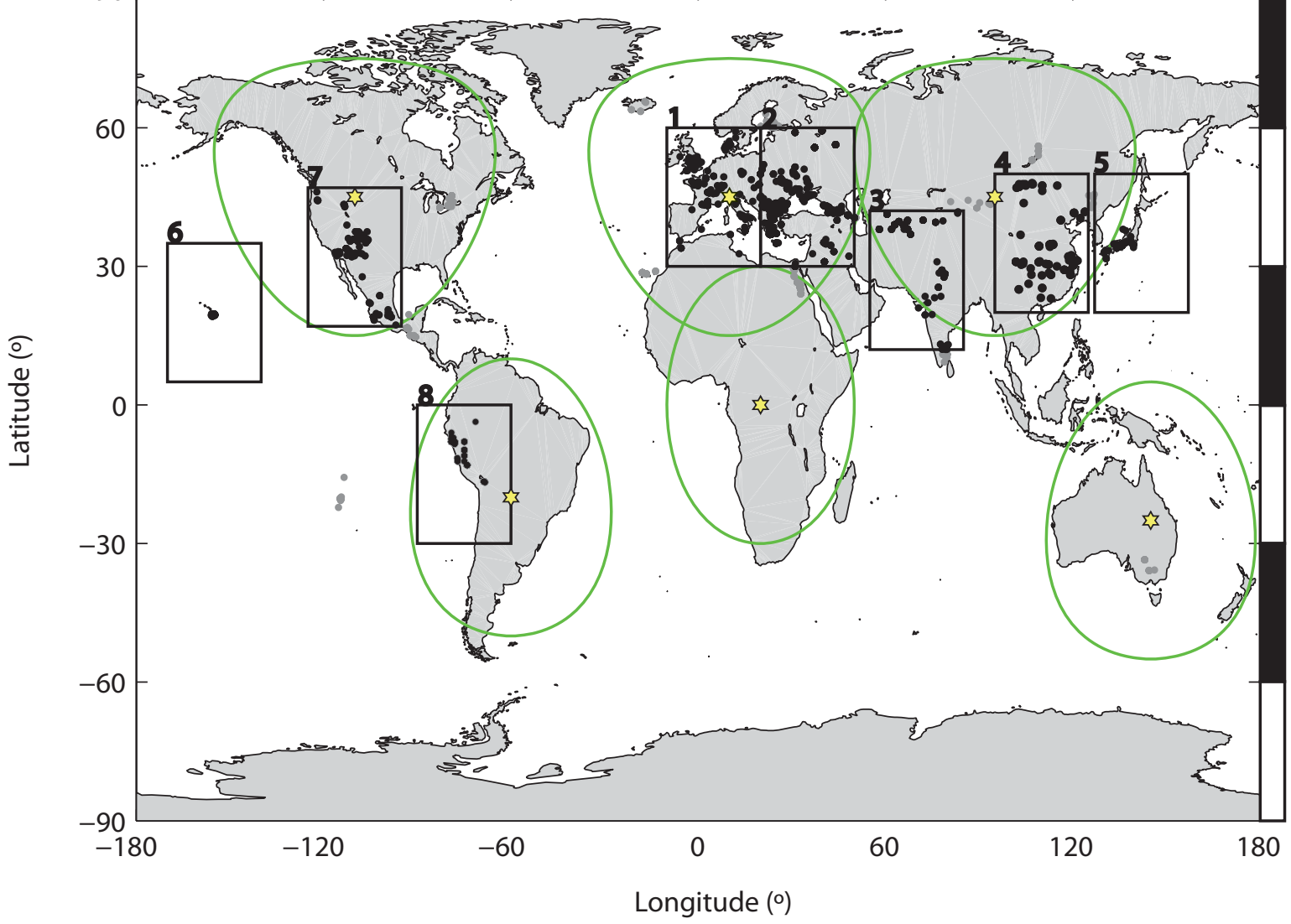




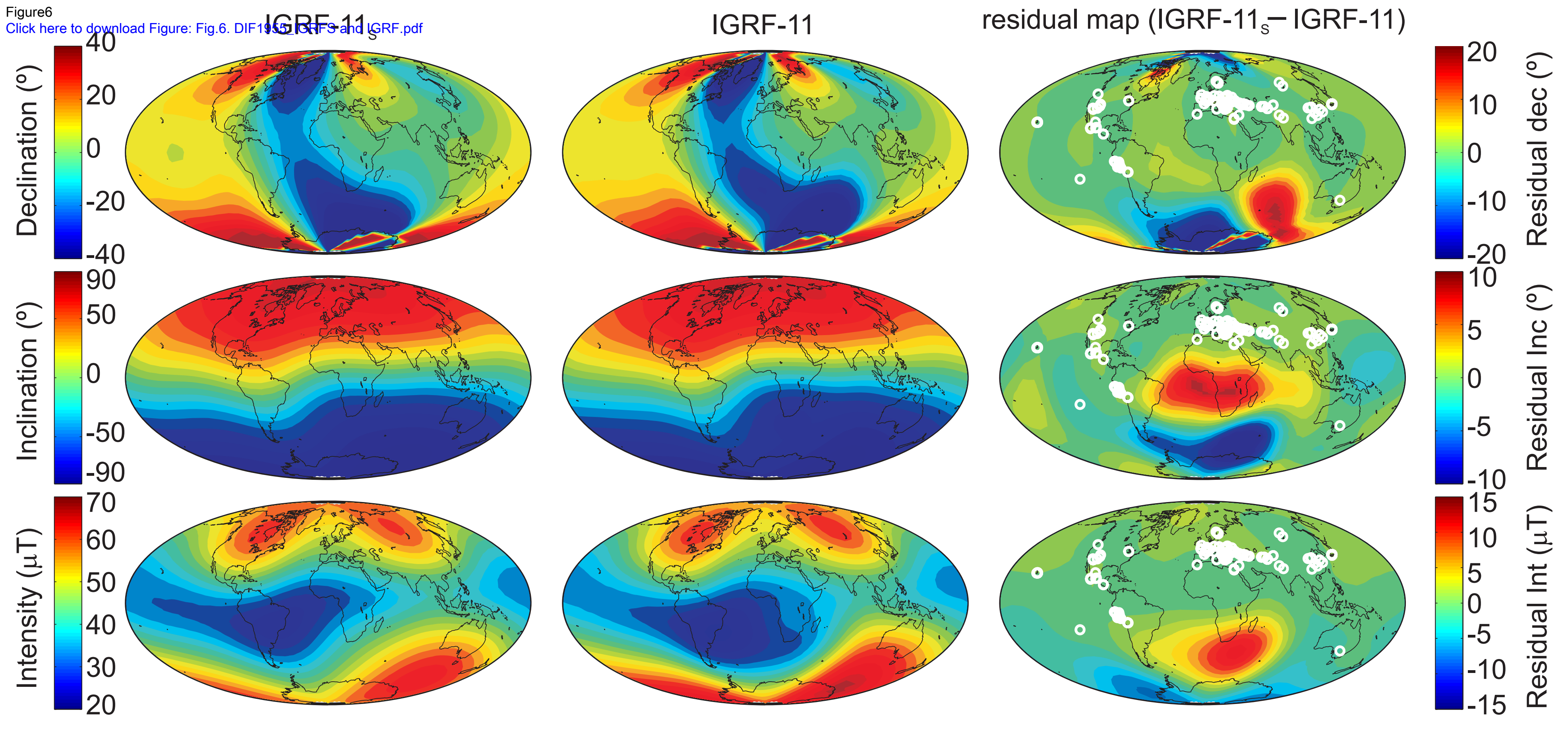


Table 1. Errors (rms) of V(A)DM $\mathrm{DM}_{\text {continental }}$ estimations for the period of 1900-2010. The (axial) regional effect, (A)RE, are computed from Eqs. 8 and 9.

\begin{tabular}{|c|c|c|}
\hline Regions & $\begin{array}{c}\text { Axial regional effect, } \\
\text { ARE-rms (\%) }\end{array}$ & $\begin{array}{c}\text { Regional effect, } \\
\text { RE-rms (\%) }\end{array}$ \\
\hline North America & 16.24 & 4.97 \\
\hline $\begin{array}{c}\text { Europe and Northern } \\
\text { Africa }\end{array}$ & 4.16 & 3.74 \\
\hline Asia & 14.53 & 14.36 \\
\hline South America & 20.06 & 15.69 \\
\hline Africa & 3.15 & 4.27 \\
\hline Oceania & 35.29 & 18.96 \\
\hline
\end{tabular}


Table 2. Errors (rms) of regionally weighting averaged $\mathrm{V}(\mathrm{A}) \mathrm{DM}\left(\mathrm{V}(\mathrm{A}) \mathrm{DM}_{\mathrm{W}}\right)$ estimations for the period of 1900-2010 and the V(A)DM without regional weighting scheme, together with the error band (confidence level of $\sim 65 \%$ ). The comparisons are developed in function on (A)DM for the same temporal interval.

\begin{tabular}{|c|c|c|}
\cline { 2 - 3 } \multicolumn{1}{c|}{} & \multicolumn{2}{c|}{ Sliding Windows } \\
\hline rms (\%) & 20 years shifted by 10 years & 10 years shifted by 5 years \\
\hline $\mathrm{VADM}_{\mathrm{w}}$ & $6.6 \pm 1.6$ & $6.6 \pm 2.4$ \\
\hline $\mathrm{VADM}^{\mathrm{V}}$ & $4.6 \pm 0.7$ & $4.8 \pm 1.0$ \\
\hline $\mathrm{VDM}_{\mathrm{w}}$ & $6.0 \pm 1.7$ & $6.0 \pm 2.5$ \\
\hline $\mathrm{VDM}$ & $3.9 \pm 0.9$ & $4.0 \pm 1.3$ \\
\hline
\end{tabular}


Table 3. Errors (rms) for the deviation between ADM and DM of the geomagnetic field calculated with the Gauss coefficients of IGRF-11 s and IGRF-11 models from 1900 to 2010 , every 5 years, together with the error band (confidence level of $\sim 65 \%$ ).

\begin{tabular}{|c|c|}
\hline & rms (\%) \\
\hline $\mathrm{ADM}_{\mathrm{S}}$ & $0.7 \pm 0.2$ \\
\hline $\mathrm{DM}_{\mathrm{S}}$ & $0.8 \pm 0.1$ \\
\hline
\end{tabular}


Supplementary Material Fig1S
Click here to download Supplementary Material: Fig.1S. Non-dipole effect-degree.pd

Supplementary Material Fig1S
Click here to download Supplementary Material: Fig.1S. Non-dipole effect-degree.pdf

Supplementary Material Fig1S
Click here to download Supplementary Material: Fig.1S. Non-dipole effect-degree.pdf

(1)

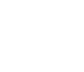

(1)

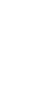

$\sqrt{3}$ (1) (1) .

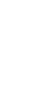

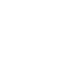

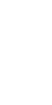

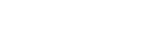
$+$ -

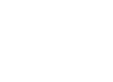

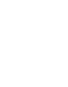

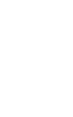
.

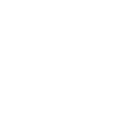
.

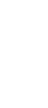



Supplementary Material Fig2S
Click here to download Suppler

Click here to download Supplementary Material: Fig.2S.VADMVDMS_VentanasTemporales_Regiones_pageoph.pdf

(1)


Click here to download Supplementary Material: Figure 3S.pdf

(n)

(2)

(2)

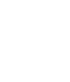

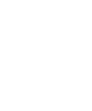

. 
Supplementary Material Table1S
Click here to download Supplementary Material: Table 1S.docx

Supplementary Material Table1S
Click here to download Supplementary Material: Table 1S.docx

Material: Table 1S.docx

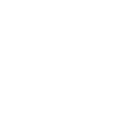
. (

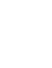

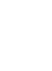
$x^{2}$ $x^{2}$

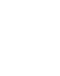
(n)

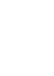

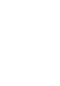

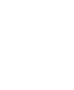

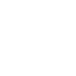
$x^{2}$ $x^{2}$ $x^{2}$ $x^{2}$ $x^{2}$ $x^{2}$ $x^{2}$ $x^{2}$ $x^{2}$ . . . . . . . . . . 